\title{
Initial Model for Fires in the World Trade Center Towers
}

\author{
RONALD G. REHM, WILLIAM M. PITTS, HOWARD R. BAUM, DAVID D. EVANS, \\ KULDEEP PRASAD, KEVIN B. MCGRATTAN, and GLENN P. FORNEY \\ Building and Fire Research Laboratory \\ National Institute of Standards and Technology (NIST) \\ Gaithersburg, Maryland, 20899, USA
}

\begin{abstract}
Based on preliminary assumptions and analysis, mathematical models have been used to estimate the behavior of the fires in the twin towers of the World Trade Center (WTC) on September 11, 2001. The hijacked-plane collision with each tower produced significant structural damage, generated a spectacular external fireball, and started burning within the tower. The fuel consumed by the fireball was lost as an ignition source, but produced a pressure pulse that broke windows and changed the ventilation for the fires. The subsequent fire in each tower generated a quasi-steady, wind-blown smoke plume. The fire and smoke behavior were simulated using the Fire Dynamics Simulator (FDS). Comparison of the observed plume trajectory with the simulated one allowed us to estimate that the rate of energy supplied by the fire to the plume was of the order of magnitude of a gigawatt $(\mathrm{GW})$. The rate of energy supplied to the plume, plus the energy-loss rate, determine the total heat release rate (HRR), the most important single parameter for each tower fire. Two bounding scenarios for the interior damage and fuel distributions were assumed for the north tower. For each scenario, the simulated visible fire and smoke behavior outside the tower were compared with the photographic and video records to determine which scenario seemed more appropriate. The simulations for the two scenarios also provided estimates of the likely thermal environment within each tower.
\end{abstract}

KEY WORDS: Computational fluid dynamics, Fire simulations, Mathematical models

\section{INTRODUCTION}

On the morning of September 11, 2001, each of the twin towers of the World Trade Center in New York City was attacked by a hijacked commercial airplane and was destroyed by a combination of the plane impact and fire ignited by the fuel aboard each plane. This is the first time that high-rise buildings have been destroyed in such a manner, and experts have been assembled to determine the cause of each collapse. As part of this effort, the Building and Fire Research Laboratory (BFRL) of the National Institute of Standards and Technology (NIST) has begun to investigate the structural collapse and to model the fire and smoke behavior. This paper describes initial efforts, based on preliminary assumptions and analysis, to model the fire behavior using the Fire Dynamics Simulator (FDS), a widely-used, NIST-developed computational model for simulating fire phenomena [1] - [6]. This NIST 
research was carried out in conjunction with the FEMA/ASCE effort, and the first findings presented here are consistent with those reported in the FEMA/ASCE World Trade Center Building Performance Study [7].

Because both towers were so completely destroyed when they collapsed, relatively little physical evidence remained for investigation. As a result, photographs and videos have become the primary resource for providing initial estimates of the exterior damage to each building and of progression of the fires. Meteorological quantities (wind speed, wind direction, pressure and temperature) as functions of height, obtained from the Aircraft Communications Addressing and Reporting System (ACARS), were also found to be critical input for the study.

The collision with each tower produced significant structural damage, generated a large, luminous external fireball with a portion of the jet fuel, and spread widely the remaining fuel, which acted as an ignition source for the combustible material within the tower. The fraction of the jet fuel consumed by the fireball was lost as an ignition source, but generated damage beyond that caused by the impact through a pressure pulse that broke windows and increased the ventilation for the fires. After this initial transient, the fire produced a quasi-steady buoyant smoke plume, which was carried along by the ambient wind. The fire and smoke behavior were simulated using FDS and compared with the observed plume trajectory, generating an estimate of the rate of energy supplied by the fire to the plume. This convective energy rate plus the energy loss rate determine the overall heat release rate (HRR), the most important characteristic for each fire.

Two bounding scenarios for the interior damage and fuel distributions were postulated, and for each scenario, simulations were performed using FDS. Then the fire and smoke behavior visible outside the towers were compared with photographic and video records to determine which scenario seemed more appropriate. The simulations for the two scenarios also provided estimates of the likely thermal environment within each tower.

\section{ORIENTATION AND DESCRIPTION OF THE TOWERS AND PLANES}

Prior to the attack, the World Trade Center (WTC) consisted of a collection of buildings of differing sizes located in lower Manhattan, as shown in the map in the upper left corner of Figure 1. The north and south towers were the tallest buildings on the New York City skyline and were a symbol of the city as well as a significant tourist attraction. Geographic north is shown on the map in Figure 1 as an arrow at the left of the map, and is nearly parallel to the left-bounding street (West Street). On the other hand, north, as commonly understood by New Yorkers, is determined by the rectangular street grid in lower Manhattan and is straight up in the map shown in Figure 1, parallel to the right-bounding street (Church Street) for the WTC. The twin towers were aligned with the rectangular street grid and therefore have North (N), South (S), East (E) and West (W) faces in these street-grid coordinates.

As shown in Figure 1, each tower was 110 stories, with the north tower being $417 \mathrm{~m}$ (1368

$\mathrm{ft})$ tall and the south tower being $415 \mathrm{~m}$ (1362 ft). Each story was approximately 3.66 $\mathrm{m}$ high, with the ceiling height of $2.62 \mathrm{~m}$ and a floor/truss/ceiling thickness of $1.04 \mathrm{~m}$. 


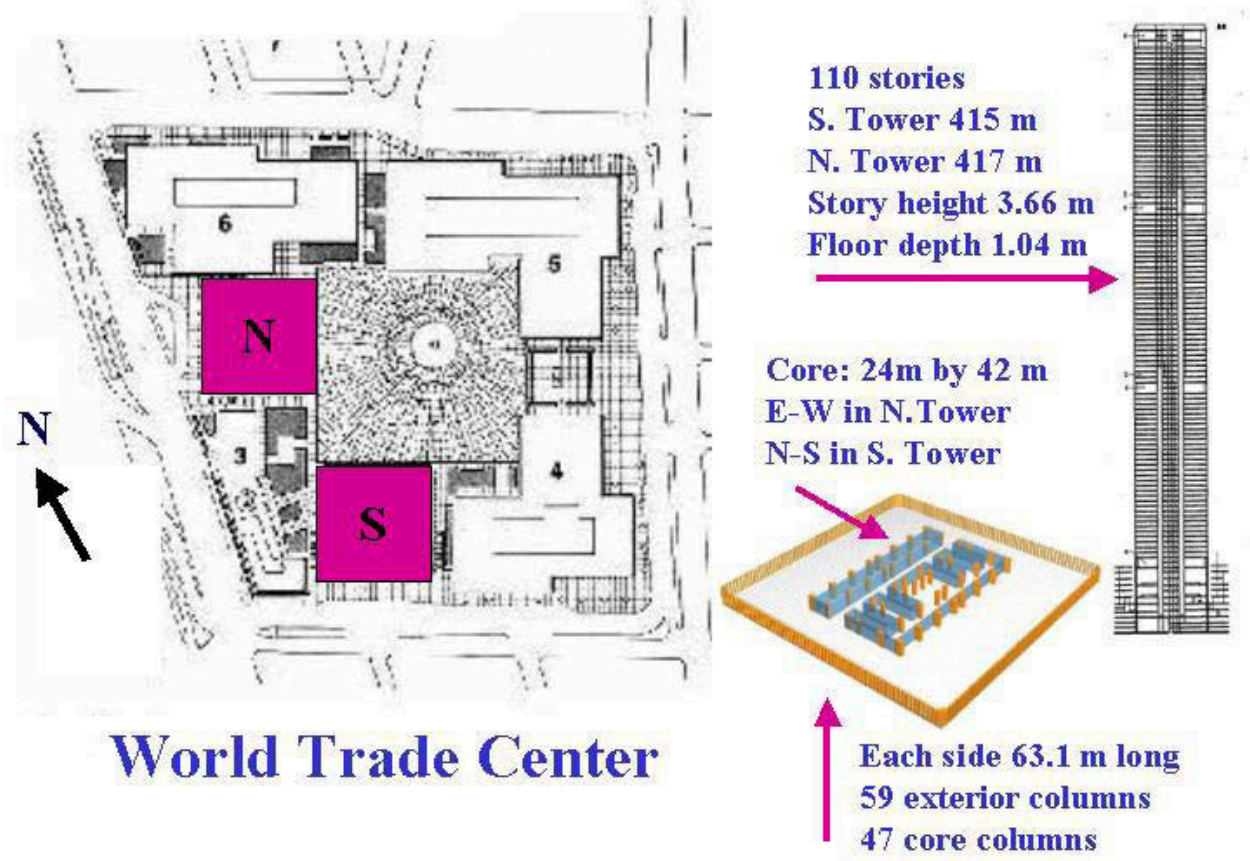

Figure 1: The layout of the World Trade Center complex and information about the twin towers. (WTC layout from web site www.greatbuildings.com. Floor layout from [8]. Vertical section of tower from [9].)

The planform of each tower was square with side $63.1 \mathrm{~m}(207 \mathrm{ft})$, also as shown in the schematic diagram of a tower floor near the center of Figure 1 [8]. Within each tower was a core measuring $24 \mathrm{~m}$ by $42 \mathrm{~m}$ composed of 47 box-section load-bearing columns. The long axis of the core in the north tower ran east and west, and that in the south tower ran north and south. The core and facade columns constituted the load-bearing structures for each tower, including the potentially high loads produced by winds. Along each exterior surface, there were 59 box-section facade columns spaced $1.02 \mathrm{~m}$ between centers [9].

The hijacked plane that hit the north tower was American Airlines, Flight 11, a 767-223ER, estimated by government sources to be carrying about 34,000 L (9000 gallons) of fuel, and flying at about $211 \mathrm{~m} / \mathrm{s}$ (470 miles per hour) [7]. The second hijacked plane was United Airlines, Flight 175, a Boeing 767-222, estimated by government sources to be carrying about $31,000 \mathrm{~L}$ ( 8200 gallons) of fuel and travelling at about $265 \mathrm{~m} / \mathrm{s}$ (590 miles per hour) [7]. The 767-200 series planes had an overall length of $48.5 \mathrm{~m}$ (159 ft 2 in), a wing span of $47.6 \mathrm{~m}(156 \mathrm{ft})$, a fuselage diameter of $5.3 \mathrm{~m}(17.5 \mathrm{ft})$, and a tail height of $15.8 \mathrm{~m}(52 \mathrm{ft})$. 


\section{IMPACT DAMAGE TO EACH TOWER}

At 8:46 AM EST, the first plane, banking to the left, collided with the north tower very close to the center of the north face between floors 94 through 99. Exterior damage to the north face extended over all six of these floors. The collision, with its accompanying fireball, produced holes in all of the other faces, some representing structural damage to the exterior support beams, while others were merely blown-out windows. For the fires, however, all of the exterior holes were important since they increased the ventilation. The initial exterior damage to the east face was seen to be confined to the lower few of these six floors, while exterior damage to the west face was primarily along the top few of these floors. The south face initially seemed to have mostly ventilation holes in a variety of places between these floors. The jet fuel seems to have ignited fires on portions of all six floors with greatest involvement on the middle floors.

At 9:03 AM, the collision of the second plane with the south face of the south tower took place, while this plane was heading slightly east of north along the Manhattan street grid. The damage pattern generated by this collision on the south face occurred over the 7 floors, 78 through 84, and was remarkably similar to that of the first collision, except that this one was not centered, but displaced to the east on the south face. Each of these patterns resembled the outline of the Boeing 767 canted at about a 30 degree angle.

The initial exterior damage to each tower was estimated using photographs and video recorded from many directions. The wind speed and direction, as well as other meteorological data, around the time of collision of the first plane with the north tower were made available to us by Michael Wyllie of NOAA [10], and required that the orientation of the towers be related to geographical north, as described earlier and shown on the map in Figure 1.

We have considered only post-impact fires and have attempted to estimate the thermal environment produced by the fires in each tower. Of particular interest are the convective heat release rate (HRR) driving the buoyant plume and maximum temperatures and heat fluxes at surviving structural elements. Estimation of the spatial and temporal distributions of the HRR, heat fluxes and temperatures are also of interest, as are the smoke and hotgas transport. Since neither the geometry nor the fuel distribution inside of either tower is known after the collision, many assumptions are required to approximate these quantities. Therefore, detailed estimates of the thermal environment within each tower are problematic. Comparisons of the output from the simulations to available photographs and videos provide constraints on estimated interior geometries and fuel distributions, but cannot discriminate entirely between different assumptions.

Within each tower, the ambient external winds, together with exterior and interior damage, and elevator shafts, stairwells and HVAC vents determine the ventilation for the fire, and, therefore, how the fire evolves. This geometry, in turn, can change with time as windows break or the fire alters the structure. Through detailed study, we have been able to identify the directions from which available photographs and videos were taken, and to estimate the exterior damage on each face of the north and south towers. Smoke obscuration was often 
a limiting factor in this assessment. At this stage of our studies, we have not yet been able to determine how the external damage changed as a function of time. Therefore, the estimate of the exterior damage used herein was determined from the mosaic of visuals obtained over the duration of the fires. As additional photographic and video evidence has become available, we have begun to refine this initial assessment and to estimate temporal changes in the exterior damage. An example is presented below of how high quality photographic and video records of the external fire behavior may help to discriminate between very different assumptions concerning interior damage and fuel distributions.

\section{THE MATHEMATICAL MODEL}

We used FDS, a computational model developed over many years specifically to study fire behavior in buildings. This model has two different ways in which it treats combustion and radiative transport. The basic hydrodynamics is treated the same manner for both versions of the code.

The flow is governed by the conservation of mass, momentum and energy, and these conservation equations are approximated as a thermally expandable, mixture of ideal gases [1] $-[6]$ :

$$
\begin{aligned}
\frac{\partial \rho}{\partial t}+\nabla \cdot(\rho \mathbf{u}) & =0 \\
\rho\left(\frac{\partial \mathbf{u}}{\partial t}+\nabla\left(\mathbf{u}^{2} / 2\right)-\mathbf{u} \times \omega\right)+\nabla p & =\rho \mathbf{g}+\mathbf{f}+\nabla \cdot \tau \\
\frac{\partial}{\partial t}(\rho h)+\nabla \cdot(\rho h \mathbf{u})-\frac{\partial \mathbf{p}_{\mathbf{0}}(\mathbf{z})}{\partial \mathbf{z}} & =\dot{q}^{\prime \prime \prime}+\nabla \cdot \mathbf{q}_{\mathbf{r}}+\nabla \cdot \mathbf{q}
\end{aligned}
$$

In these equations, all of the symbols have their usual fluid-dynamical meanings. For example, $\rho$ is the gas density, $\mathbf{u}$ is the fluid velocity (a vector quantity as noted by the boldface symbol), $p$ is the pressure, $\omega=\nabla \times \mathbf{u}$ is the vorticity, $\mathbf{g}$ is the acceleration of gravity, $\rho \mathbf{g}$ is the body force per unit volume due to buoyancy and $\mathbf{f}$ is an external body force per unit volume representing drag imposed by quantities external to the fluid, $h$ is the enthalpy per unit mass, $T$ is the temperature, and $\mathbf{q}_{\mathbf{r}}$ and $\mathbf{q}$ are the radiative and convective heat fluxes respectively. The flow is driven primarily by the heat release rate $\dot{q}^{\prime \prime \prime}$ arising from the combustion.

These equations have been recast and approximated to simplify them for the numerical computation of fire phenomena. A complete discussion of these approximations and of the numerical methods used in their solution is available [1], [4]. In one version, combustion is treated by the thermal element method (TEM) [11]. In this method, the combustion is formulated as a coupled Lagrangian, Eulerian description, with the combustion characterized by gaseous Lagrangian fuel parcels, which are released into the gas at a prescribed rate from a burning surface and then burn as a specified function of time. These Lagrangian parcels are, in turn, carried by the flow field, releasing their heat back into the grid-based description of the fluid flow. In this way, a two-way coupling is achieved between the combustion and the buoyant flow. Also, in this version, radiation transport is treated in the optically thin limit. As fuel parcels burn, a fraction of the released energy is radiated away, to be 
intercepted by solid boundaries in the flow or to escape from the computational domain. While the first version of FDS has been found to be computationally efficient and useful for many purposes, it has not allowed the proper feedback between the burning gaseous fuel and a burning solid surface.

By contrast, the other version uses a strictly Eulerian, mixture-fraction formulation to describe the combustion. In this model, the flame sheet is found where stoichiometry occurs, and the heat from the exothermic reaction is released into the flow along the flame sheet. The radiative transport is also handled in a more sophisticated fashion. An approximate solution to the full radiation transport equation, that accounts for local absorption and reradiation by the material in the computational domain, is used to calculate radiative fluxes and, therefore, heat transfer by radiation. This formulation allows the radiation coupling that generates new gaseous fuel at solid surfaces.

Detailed descriptions of the mathematical models used in both versions, and of the methods used to validate them, are presented in the reports of McGrattan et al [1], [2] and the references therein. These reports plus some of the references can be downloaded from the BFRL website, http://fire.nist.gov. The companion visualization code known as Smokeview, is described in detail in the reports of Forney and McGrattan [3], [6], which are also available on this website. The quality and ease of use of this visualization tool have significantly improved our ability to understand fire behavior. Object codes for both FDS2 and Smokeview, as well as user manuals for each code [1] - [6], and examples of applications are also available on this website.

\section{METEOROLOGY}

The trajectory of the smoke plume can be used, in principle, to estimate the magnitude of convective energy per time contributed to the smoke plume by the tower fires. This convective energy rate, the wind speed and direction, and atmospheric stability are the parameters known to govern a smoke-plume trajectory [12].

From photographs and videos, we determined that the wind direction was almost exactly from the geographic north. We also established that the velocity of this wind was between $5 \mathrm{~m} / \mathrm{s}$ and $10 \mathrm{~m} / \mathrm{s}$. The wind speed and direction were verified by data from the Aircraft Communications Addressing and Reporting System (ACARS), which also provided data on temperature and pressure as functions of height. From these data, assuming a perfect gas, one can also calculate air density as a function of height, and these thermodynamic quantities determine the stability of the atmosphere. Commercial flights generally use ACARS to capture and report temperature, pressure and wind speed and direction data as functions of altitude [10]. Figure 2 shows these quantities on the morning of 9/11 as obtained from three flights, one from JFK airport in New York and the other two from Newark International in New Jersey. We used $5 \mathrm{~m} / \mathrm{s}$ as the wind velocity and a lapse rate approximately one half the adiabatic lapse rate, which is $-1.0^{\circ} \mathrm{C}$ per $100 \mathrm{~m}$.

While a full fuel load for each plane would be approximately $90,800 \mathrm{~L}$ or $74,500 \mathrm{~kg}$ of jet fuel, as noted earlier, the planes carried only approximately 31,000 to $34,000 \mathrm{~L}$ or 26,000 to $28,000 \mathrm{~kg}$ of jet fuel (density $\rho_{\text {fuel }}=0.82 \mathrm{~kg} / \mathrm{L}$ ). The area of one floor of either tower 

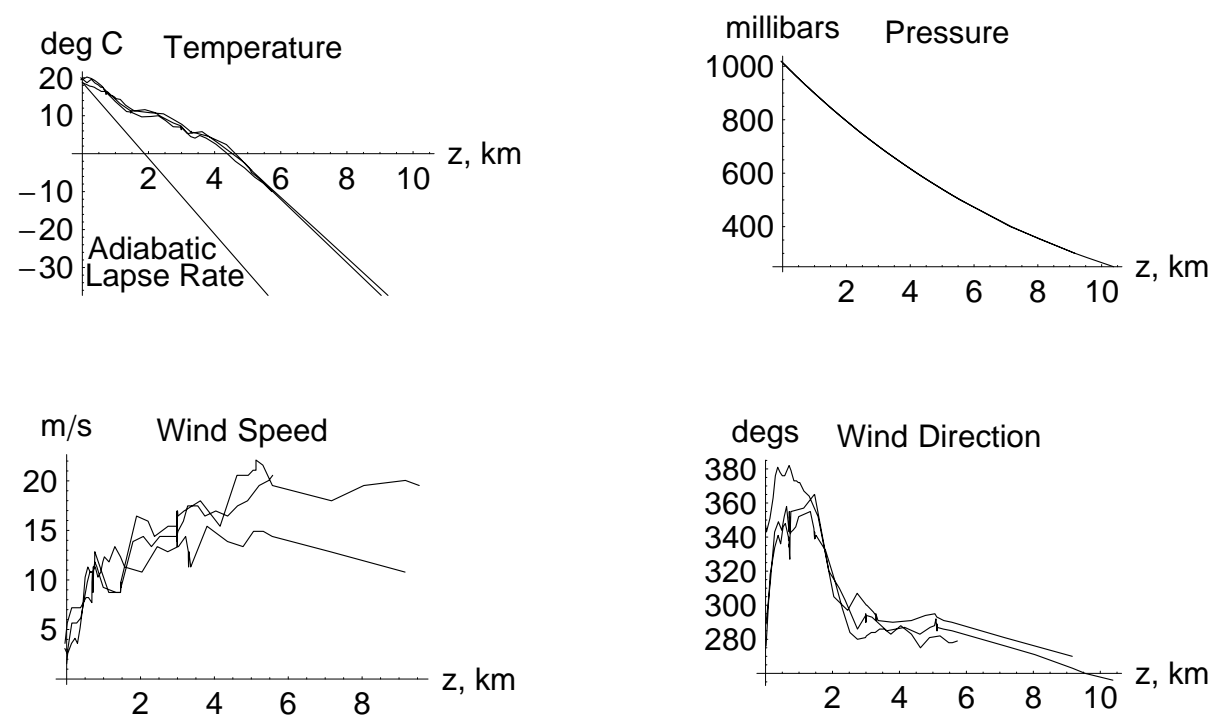

Figure 2: Temperature and pressure profiles as functions of altitude on September 11, 2001, around the time of the first plane crash. Also shown are plots of wind speed and direction as functions of altitude. These data were obtained from three commercial flights in the New York City area using the Aircraft Communications Addressing and Reporting system (ACARS) [10].

was $4025 \mathrm{~m}^{2}$. For a large over-ventilated jet-fuel pool fire, the heat release rate per unit area is reported to be approximately $2 \mathrm{MW} / \mathrm{m}^{2}$ [13]. As one limiting scenario, we consider that the plane dumped its whole fuel load over only one floor (smashing all material on that floor, including both combustible and non-combustible matter). Then the fuel would cover this floor to an average depth of nearly $0.8 \mathrm{~cm}$, and the fuel load per unit area would be approximately $6.2 \mathrm{~kg} / \mathrm{m}^{2}$. In this case, we consider the fuel to be instantaneously ignited and begin burning with a heat release rate of approximately $2 \mathrm{MW} / \mathrm{m}^{2}$, yielding a total heat release rate in this scenario of several GW. At this burning rate, the jet fuel would be consumed in only a few minutes, assuming an adequate air supply, and even in less time if the fuel were spread over a greater area. These estimates are consistent with those given in the FEMA/ASCE study [7] and are important because they demonstrate that the jet fuel would be consumed quickly relative to the duration of the tower fires.

The design load for one floor of such a building is usually taken to be $460 \mathrm{~kg} / \mathrm{m}^{2}$ with 90 $\mathrm{kg} / \mathrm{m}^{2}$ due to partitions and $370 \mathrm{~kg} / \mathrm{m}^{2}$ regarded as movable. Of this movable load, the combustible portion is generally taken to be 14 to $18.5 \mathrm{~kg} / \mathrm{m}^{2}$, but possibly ranging up to $140 \mathrm{~kg} / \mathrm{m}^{2}$, with an average load of $46 \mathrm{~kg} / \mathrm{m}^{2}$ still being reasonable in an office building such as the WTC Towers, where paper work is the dominant activity [14]. Therefore, a very reasonable way to look at these fires is to consider the burning jet fuel to be the igniter of the existing fuel within the building. It must also be noted that the fuel loads might vary considerably with spatial location in each building. 


\section{PLUME-TRAJECTORY SCALING}

In a series of papers by the authors, [12], [13], [15], modern CFD methods were used to calculate atmospheric dispersion of combustion products downwind of large, outdoor oil fires. The mass, momentum and energy equations stated above can be simplified by assuming a steady, non-zero horizontal wind blowing over a fire of heat release rate $Q$, assumed to be constant. $Q$ is the most important parameter characterizing an outdoor fire, independent of the specific fuel. Ambient stratification of the atmosphere, which is related to the meteorological concept of potential temperature, is included in this model. The atmospheric stability at any height is determined by the local density (or temperature) gradient and is specified by the local buoyancy frequency $N=\sqrt{(g / \rho(z))(d \rho(z) / d z)}$. This frequency arises because the atmosphere is naturally stratified as a function of height, with the highest density air at ground level and smaller densities with increased height. The horizontal velocity is assumed to be uniform with height over the height of interest, although the more general theory allows for a velocity profile changing with height [15]. Analytical scaling of the governing equations introduced in these papers yields the following important length scale:

$$
L=\left(\frac{Q g}{C_{p} T_{\infty} \rho_{\infty} U N^{2}}\right)^{1 / 3}
$$

where $U$ is the steady and uniform horizontal velocity, $N$ is the buoyancy frequency defined above, $C_{p}$ is the constant-pressure specific heat for air, and $T_{\infty}$ and $\rho_{\infty}$ are the ambient, ground-level temperature and density. This length must be interpreted as an estimate of the order of magnitude of the height above the fire to which the centerline of the plume will rise for the specified values of the fire size $Q$, the wind speed $U$ and the buoyancy frequency $N$. Because this relationship is derived from the governing equations, it should apply to the WTC tower fires as well as to oil-spill fires.

For the meteorological conditions on the morning of 9/11, shown in Figure 2, the characteristic height $L$ is plotted in Figure 3 as a function of the rate of energy driving the plume $Q$ for different values of the buoyancy frequency and of the velocity. These plots indicate the sensitivity of this length to changes in the atmospheric stability (left) and to the wind speed (right). Comparison of this scaling with photographs of the north-tower plume suggest that lofting of this plume to hundreds of meters above the height of the fire requires that $Q$ be of the order of magnitude of a gigawatt $(\mathrm{GW})$.

One very important cautionary note is that the length scale defined and discussed above, and the simulations reported below, address only the convective energy per unit time that drives the quasi-steady plume. It does not determine the rate at which heat is released by the fire in each tower. Rather, a fraction is lost by radiation out of each tower, another portion heats the structure itself, and the remainder is convected out of the tower and into the plume $(Q$.

In the next subsection, FDS simulations are described, and the convective energy per unit time going into the plume is also estimated to be in the gigawatt range. 

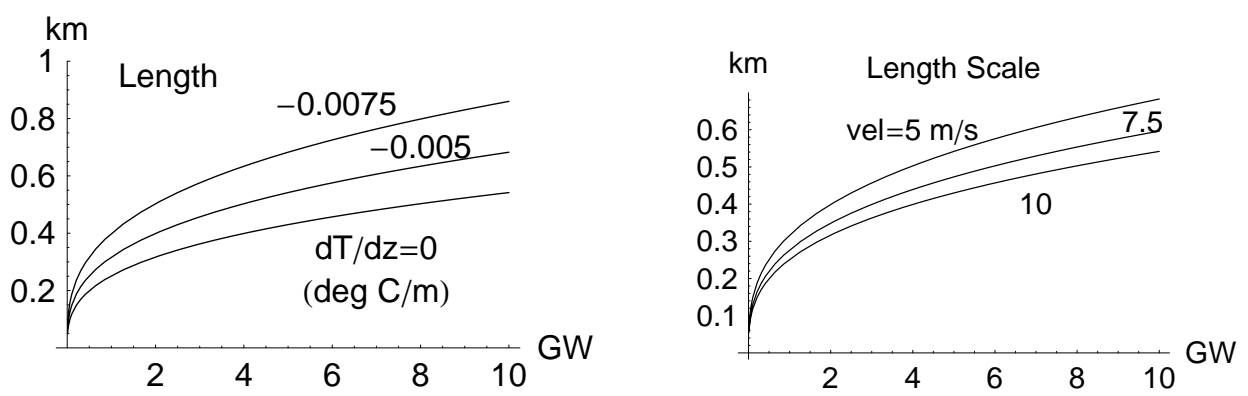

Figure 3: The two plots above show the plume scaling height $L$ as functions of the convective energy per time $Q$. They indicate the sensitivity of this length to changes in the buoyancy frequency or temperature gradient (left) and to the wind speed (right). The base case uses $d T / d z=\mathbf{- 0 . 0 0 5}{ }^{\circ} \mathrm{C} / \mathrm{m}$, and velocity $=\mathbf{5} \mathrm{m} / \mathrm{s}$.

\section{PLUME-TRAJECTORY CALCULATIONS}

Two types of computations have been performed, one using the thermal element model and the other using the mixture-fraction model for combustion. The first types were performed over a domain which included the top portions of both towers and horizontal lengths in each direction equal to a few tower heights. With these computations, we attempted to bound the total quasi-steady convective heat release from the fires in each tower by comparison of the observed smoke plume trajectory with that determined by the simulations. The second type of simulation used the mixture-fraction combustion model to characterize the fire behavior in the damaged portion of each tower.

For most of the simulations reported here, a grid of 108 nodes in each direction $\left(1.26 \times 10^{6}\right.$ total cells) was used. Such computations required about $15 \mathrm{CPU}$ hours on a $1 \mathrm{GHZ}$ standard personal computer (PC) to simulate $500 \mathrm{~s}$ real time for the FDS1 computations and about 30 $\mathrm{s}$ real time for the FDS2 computations. The domain for the FDS1 computations was taken to be $600 \mathrm{~m}$ in both horizontal directions by $800 \mathrm{~m}$ in the vertical direction, giving a cell size of $5.6 \mathrm{~m}$ by $5.6 \mathrm{~m}$ by $7.4 \mathrm{~m}$. The domain for the FDS2 simulations was approximately $84 \mathrm{~m}$ by $84 \mathrm{~m}$ by $70 \mathrm{~m}$, giving a cell size of $0.78 \mathrm{~m}$ by $0.78 \mathrm{~m}$ by $0.65 \mathrm{~m}$.

Using these atmospheric parameters, we found that the rate of energy released into the plume gases was of the order of magnitude of a gigawatt and was consistent approximately with the observed quasi-steady plumes. For rates an order of magnitude larger, the steadystate plume height increased too quickly with downwind distance, whereas for rates an order of magnitude smaller, the plume height did not increase quickly enough with downwind distance.

In Figure 4 a photograph of the smoke plume from the WTC tower fires and a simulation, using FDS1 of the smoke plume from these fires are shown together for comparison. The agreement between the trajectories appears reasonable and indicates that the rate of energy supplied to the smoke plume is of the order of magnitude of a gigawatt. 


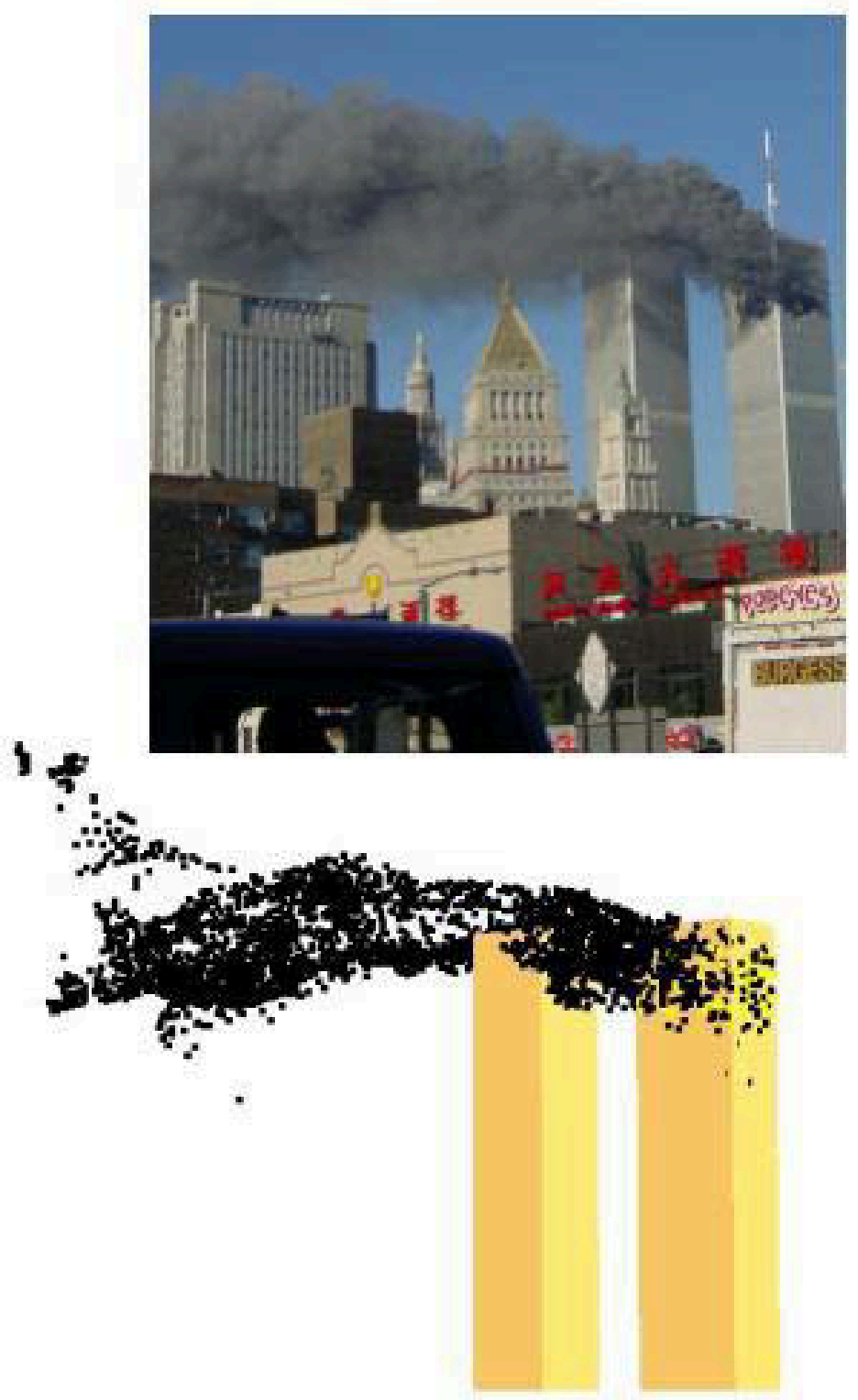

Figure 4: Comparison of a photograph ( (c)2001 Kevin Ready. All rights reserved. Used by permission.) and of a frame from simulation of the WTC tower fires, showing the quasisteady smoke plume generated by the fire in the north tower. 


\section{SIMULATIONS OF FIRE BEHAVIOR WITHIN EACH TOWER}

Now we turn to the second type of simulation. These simulations demonstrate the importance of obtaining a good estimate of the exterior damage, as well as reasonable postulates for the interior geometry and fuel distribution for each tower. It is assumed that better estimates for all of these quantities will produce simulations with exterior flames and smoke matching more closely those quantities in the photographic and video records. Furthermore, it is assumed that better matching of these external observations will also yield better estimates for the thermal environment inside the tower.

We note that generating good estimates for the external and internal damage geometries as well as the internal fuel distribution is very difficult. We have studied a wide variety of photographs and videos to determine the damage to the outside faces of each tower. We think that we have a representative approximation to the exterior configuration estimated over the time that the towers burned. We have acquired this approximation despite the smoke obscuration, the changing geometry or damage with time (as the fire causes windows to break and the structural elements to soften and yield), and the limited views we have of some of the faces.

For both undamaged towers, we modeled a story as having a total height of $3.66 \mathrm{~m}$, with a floor/truss thickness/ceiling combination of $1.04 \mathrm{~m}$. Only a portion of the height of each tower was included in the simulations. The model started two stories below the damaged ones and ended ten stories above, because buoyancy causes the smoke and hot gas to rise. For the north tower, for example, the model began at the 92nd story and included the 108th story. The south tower began at the 76th story and ended at the 93rd story. The outside walls of the undamaged stories of each tower were impenetrable, whereas the core was assumed to be open at both the top and bottom allowing gases to flow freely in and out.

The core, which had a different orientation in the two towers as noted above, was modeled by two vertical shafts each extending $42 \mathrm{~m}$ in the direction of the long axis of the core, one having a width of $2.5 \mathrm{~m}$ and the other a width of $14.6 \mathrm{~m}$, with a $7.4 \mathrm{~m}$ aisle separating the two. The larger shaft was taken to be hollow, with a slit of $3.2 \mathrm{~m}$ running vertically up the center of both long faces of the shaft. These slits were constructed to represent openings (about 5 percent of the perimeter of the shaft) connecting floors vertically through the core, and can be regarded as a combination of designed vertical connections and damage produced connections. As noted above, the core shaft was open at both the bottom and the top of the model. It was found that the hot gases tended to enter this shaft and to rise as in a chimney. The slit size in the core shaft changes the interior ventilation for the model, and this interior ventilation should be varied systematically to determine its importance to the spread of smoke, hot gases and the fire. Only two cases were simulated, one with no slits in the core and the other with the $3.2 \mathrm{~m}$ slits described above. The only general conclusion drawn by comparing these two cases was that the chimney effect could be observed when the slits were included.

Damage and the fuel distribution on the inside of the tower must be postulated. As an attempt to bracket the interior damage, we assumed two very different damage scenarios for a segment of the north tower. For the first scenario, it was assumed that five floors were 

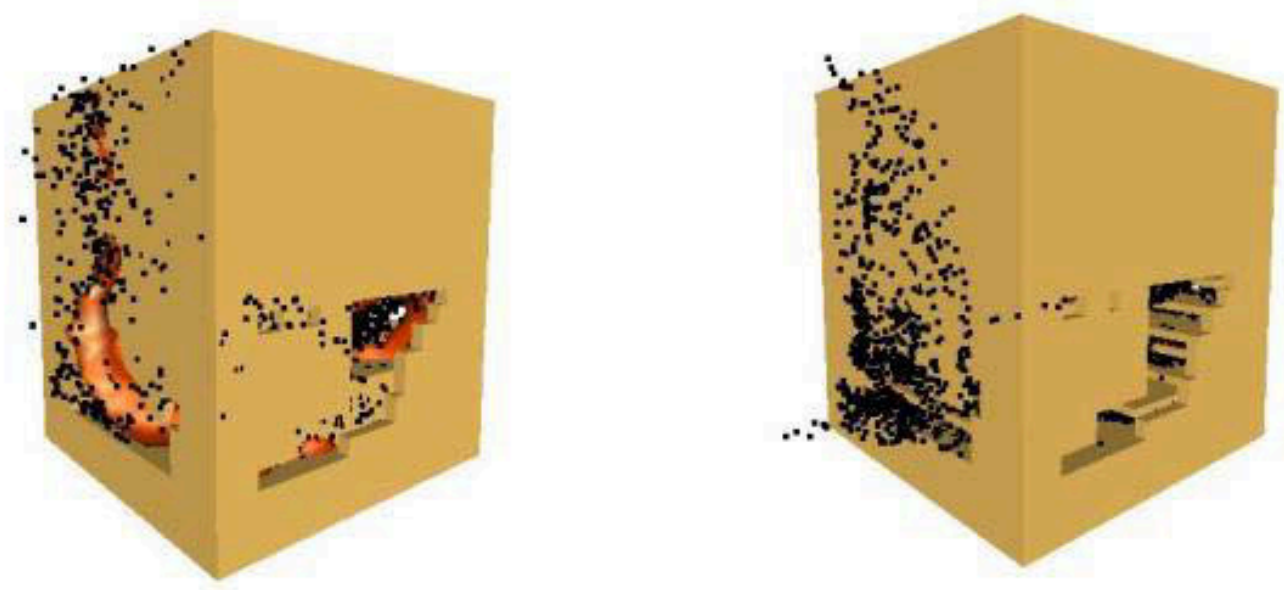

Figure 5: A comparison of two simulations of the fire in the north tower, with very different assumed internal damage geometries and fuel distributions. The left simulation shows very large flames extending from the damage holes, whereas that at the right shows little flame extending out of the exterior damage holes. The simulation on the right seems to agree much more with pictorial records, indicating that these postulates are better. 
damaged and collapsed into a pile of combustible rubble from the force of initial impact, the north face, to the core. Therefore, the damage geometry was effectively one large open space with the rubble treated as a big rectangular block on the floor. We assumed that the internal combustible material was spread uniformly over all of the interior surfaces in the damaged area including the block, and all surfaces burned at the same rate.

In a second case, it was postulated that the plane penetrated to the core of the north tower and that the floors remained standing up to the damage hole produced by the plane. In this case, most of the floor area, except for the plane hole remained as it was before the collision, and the fire burned over these long, narrow floors.

Figure 5 shows a snapshot of the two fires in these contrasting scenarios. The plot at the left shows the simulated fire in the first scenario. The plot at the right shows the fire for the second scenario. We note that in the right plot, the flames extend only slightly out of the exterior damage holes, in sharp contrast with the simulated flames in plot at the left. The simulation on the right seems to agree much more with pictorial records, indicating that the second postulated scenario of the interior damage and fuel distribution is better.

\section{SIMULATIONS OF SOUTH TOWER FIREBALL}

Finally, we show results of a simulation of the fireball generated immediately after the collision of the second plane with the south tower. The fireballs technically are found to be deflagration waves, since the flame propagation speed of the fireballs observed from videos approached only a small fraction of the sound speed of the ambient air. From videos of the second plane colliding into the south tower, the fireball was found to expand the width of the building (about $63 \mathrm{~m}$ ) in about one second, yielding a propagation speed of about 60 $\mathrm{m} / \mathrm{s}$. For comparison, the local sound speed at $20^{\circ} \mathrm{C}$ is about $348 \mathrm{~m} / \mathrm{s}$. Therefore, fireballs were deflagrations of the mixed and burning jet-fuel/air combination immediately after the collision. The fireballs observed outside each tower arose when the interior burning gases expanded rapidly and pushed fuel out of the tower where it subsequently burned.

Figure 6 shows a comparison of photograph of the observed south-tower fireball and a corresponding picture taken from a simulation of this fireball a few seconds after the collision. Combustion is described by the mixture-fraction model, and the fireball is simulated by introducing a very large heat release rate over a short time so that the total energy released during the life of the fireball conforms to that estimated from the videos of the event.

\section{SUMMARY AND CONCLUSIONS TO DATE}

Mathematical models have been used to estimate properties of the fires in the twin towers of the World Trade Center on September 11, 2001. Photographs and videos have provided an approximation to the exterior damage to each building. Profiles of meteorological quantities (wind speed, wind direction, pressure and temperature) as functions of height have also been extremely important data. The collision with each tower produced significant structural damage, generated a large, luminous external fireball with a portion of the jet fuel and ignited the combustible material within the tower with the remainder of this fuel. 
The jet fuel consumed by the fireball does not appear to have ignited other fuel inside of the tower.

The subsequent fire in each tower produced a quasi-steady buoyant smoke plume that was carried along by the ambient wind. The fire and smoke behavior were simulated using the Fire Dynamics Simulator (FDS). Comparison of the observed plume trajectory with the simulated one indicated the rate of energy supplied by the fire to the plume was of the order of magnitude of a gigawatt. Two bounding scenarios for the interior damage and fuel distributions were assumed for the north tower. For each scenario, the simulated visible fire and smoke behavior outside the tower was compared with photographic and video records to determine which scenario seemed more appropriate. The simulations for the two scenarios also can provide estimates of the likely thermal environment, including temperatures and heat fluxes, within each tower. The estimates are subject to change as more visual records and other data become available. They could also change as additional simulations are performed and more complex models are developed and utilized.

Sensitivity studies of the effects of internal damage geometry and fuel loading should be undertaken. In addition, the fire in one tower can be influenced by the presence of the second through the outside wind fields and, as noted before, by the changed ventilation (e.g., broken windows by the pressure pulse generated by the south-tower fireball). Since the wind was from the north, the influence of the north tower on the fire in the downwind south tower is expected to be particularly significant. At present, we cannot study this coupling. In future studies, we hope to use the multiblock computational method [16], which is a computational scheme that can be much more efficient, and parallel processing on multiple CPUs to examine these effects. These improvements offer the potential for much larger simulations (ones with much higher resolution) to be performed!

\section{ACKNOWLEDGEMENTS}

The authors wish to thank Harold Nelson, consultant with Hughes Associates, and formerly with BFRL, NIST, for his detailed and critical discussions that significantly altered the emphasis and direction of this report. We also thank Jay McElroy and William D. Walton for help in acquiring quantitative information from some of the videos.

\section{REFERENCES}

[1] McGrattan, K.B., Baum, H.R., Rehm, R.G., Hamins A. and Forney, G.P., "Fire Dynamics Simulator - Technical Reference Manual," National Institute of Standards and Technology Report No. NISTIR 6467, 2000.

[2] McGrattan, K.B. and Forney, G.P., "Fire Dynamics Simulator - User's Manual,” National Institute of Standards and Technology Report No. NISTIR 6469, 2000.

[3] Forney, G.P. and McGrattan, K.B., "User's Guide for Smokeview Version 1.0 - A Tool for Visualizing Fire Dynamics Simulation Data," National Institute of Standards and Technology Report No. NISTIR 6513, 2000. 

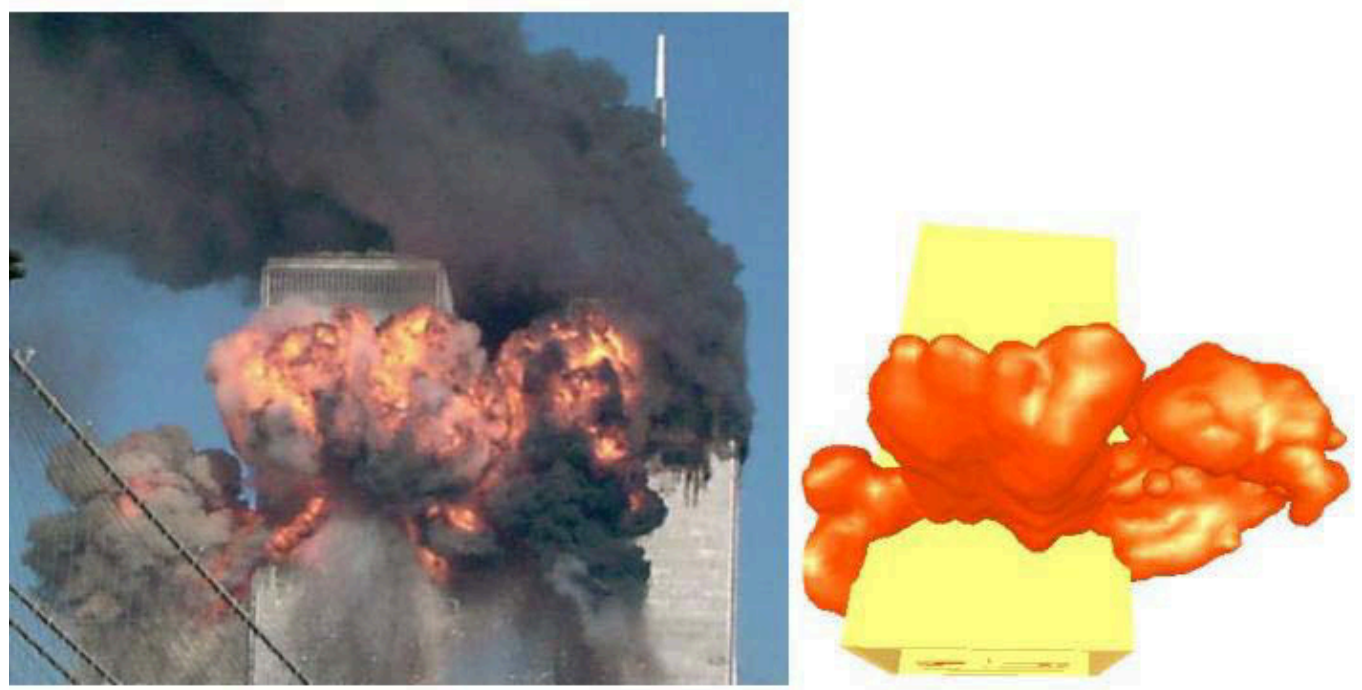

Figure 6: Comparison of a photograph ( (c)2001 Sara K. Schwittek. All rights reserved. Used by permission.) and a simulation image of the south tower fireball shortly after the collision with the second hijacked plane.

[4] McGrattan, K.B., Baum, H.R., Rehm, R.G., Hamins, A., Forney, G.P., Floyd, J.E. and Hostikka, S., " Fire Dynamics Simulator (Version 2) - Technical Reference Guide," National Institute of Standards and Technology Report No. NISTIR 6783, 2001.

[5] McGrattan, K.B., Forney, G.P., Floyd, J.E. and Hostikka, S. "Fire Dynamics Simulator (Version 2) - User's Guide," National Institute of Standards and Technology Report No. NISTIR 6784, 2001.

[6] Forney, G.P. and McGrattan, K.B., "User's Guide for Smokeview Version 2.0 - A Tool for Visualizing Fire Dynamics Simulation Data," National Institute of Standards and Technology Report No. NISTIR 6761, 2001.

[7] "World Trade Center Building Performance Study: Data Collection, Preliminary Observations, and Recommendations," FEMA Report 403, Federal Emergency Management Agency, Federal Insurance and Mitigation Administration, Washington, DC, 2002.

[8] "Arup Corporation, Briefing 2 by the Extreme Events Mitigation Task Force," Arup Report, 2001. (Arup Web Site: www.arup.com.) 
[9] Hart, F.,W. Henn and H. Sontag, "Multi-Storey Buildings in Steel," English Edition Editor G. Bernard Godfrey, Halsted Press, John Wiley \& sons, New York, 1978, 1624.

[10] Wyllie, Michael, National Weather Service, National Oceanographic and Atmospheric Administration (NOAA), Department of Commerce, Private Communication, 2001.

[11] Baum, H.R., Ezekoye, O.A., McGrattan, K.B. and Rehm, R.G., Theoretical and Computational Fluid Dynamics, 6, 1994, 125-139.

[12] Baum, H.R., K.B. McGrattan and R.G. Rehm, "Simulation of Smoke Plumes from Large Pool Fires,” J. Proc. Comb. Inst. 25 1994, 1463-1469.

[13] McGrattan, K.B., H.R., Baum, W.D. Walton and J. Trelles, "Smoke Plume Trajectory from In Situ Burning of Crude Oil in Alaska - Field Experiments and Modeling of Complex Terrain,” NIST Internal Report NISTIR 5958, 1997.

[14] Culver, C.G., "Survey of Results for Fire Loads and Live Loads in Office Buildings," Final Report, NBS BSS 085, National Bureau of Standards, 1976.

[15] Trelles, J. J.; McGrattan, K. B.; Baum, H. R., "Smoke Transport by Sheared Winds," Combustion Theory and Modelling, 3, 1999, 323-341.

[16] Prasad, K., Patnaik, G. and Kailasanath, K., “A Multiblock Technique for Simulating Fire and Smoke Spread in Large Complex Enclosures," to appear in the Fire Safety Science, Proc. 7th Int. Symp., 2002. 